\title{
The Development of a Physical Model of an Advanced Gas Cooled Reactor Core: Outline of the Feasibility Study
}

\author{
Luiza Dihoru $^{1 *}$, Olafur Oddbjornsson ${ }^{1}$, Matt Dietz', Tony Horseman ${ }^{1}$, Panos Kloukinas ${ }^{1}$, \\ Elia Voyagaki ${ }^{1}$, Adam J. Crewe1, Colin A. Taylor'1, Alan G. Steer ${ }^{2}$ \\ 1 University of Bristol, University Walk, Bristol, BS8 1TR, United Kingdom \\ 2 EDF Energy Generation, Barnett Way, Barnwood, Gloucester, GL4 3RS, United Kingdom \\ ${ }^{1 *}$ Corresponding author: Luiza.Dihoru@bristol.ac.uk
}

\begin{abstract}
The graphite components in the Advanced Gas Cooled Reactor (AGR) cores are subject to degradation processes that are predicted to lead to greater numbers of weakened and cracked components. These ageing issues need addressing to maintain their safety and reliable operation, hence the requirement for the computer models of the cores used for the seismic resilience assessments to be conservative and to represent larger percentages of damaged graphite components. The current models have undergone limited experimental validation for high levels of degradation, so there is a need to validate those numerical models and also to enhance the understanding of core dynamics by physical modelling and testing. This paper outlines the feasibility study of a quarter scale model rig of an AGR core developed by the University of Bristol. The damage scenarios to be considered in demonstrating the core seismic tolerability were defined. The principles of scale modelling were put under scrutiny in parallel with several practical aspects of material selection and component design and manufacturing. Several variants of physical models of different size and shape were proposed and their merits with respect to their feasibility and outcomes were discussed. Relevant aspects of instrumentation design are also presented. The rig is a viable experimental tool whose outputs can be employed directly in computer model validation.
\end{abstract}

Keywords: advanced gas cooled reactor, seismic resilience, physical model

\section{Introduction}

The Advanced Gas Cooled Reactors (AGR) are the second generation of British gas-cooled nuclear reactors, using graphite as the neutron moderator and carbon dioxide as the coolant. In the United Kingdom, EDF Energy Generation operates seven AGR power stations, each with two identical reactors. It is a requirement that the reactors should be safely shut down, held down and cooled down in the event of an earthquake with a probability of exceedance of $10^{-4}$ per annum. This seismic capability needs to be demonstrated throughout the stations' lives and to take account of the consequences of fast neutron irradiation and radiolytic oxidation for graphite component behaviour. These degradation processes, which include changes in geometry, strength and the possibility of differential shrinkage induced cracking have been well documented for a number of years and have been the subject of a number of conferences addressing the issues (Neighbour 2007, Neighbour 2013, Flewitt and Wickham 2015). 
It is therefore important for such degradation processes to be captured in the numerical reactor core models used to assess seismic capability and, where practicable, in the physical array models.

While it is not possible to measure directly the response of an actual Advanced Gas Cooled Reactor (AGR) core to a seismic loading of significant magnitude, full-scale physical model testing could be a potential way of assessing their seismic resilience. However, besides the excessively high cost of such an attempt, the overall dimensions of a full scale AGR core model (diameter $\sim 11 \mathrm{~m}$, height $\sim 10 \mathrm{~m}$, weight $>1000$ tonnes) could not be accommodated by any 6-DOF ('Degrees Of Freedom') earthquake simulator in Europe. Scale model testing on a shaking table is a potential way to seismically qualify the real core but only if a high confidence can be established that a direct relationship between the response of the model and that of the prototype exists. Such an approach would be valid for structures that behave elastically, provided sufficient confidence exists in all the relevant scaling laws for the fundamental properties of the model, e.g. component geometry, material density and material stiffness. However, an AGR core is a highly non-linear array of bricks and keys, in which the relevant forces are the impact forces generated during collisions between the components and the inertia driving and restoring forces due to the seismic and gravity accelerations respectively. Therefore, the solution is to employ computer modelling of the actual AGR cores to determine the expected response. Assurance is then required that the computer model is adequate and conservative in predicting reality. The role of scale model testing is to provide such assurance by experimental validation of the numerical tools.

Currently, the seismic responses of the AGR cores are calculated using the GCORE finite element (FE) model (Kralj et al 2005). GCORE uses the explicit dynamic solver, LS-DYNA. The GCORE approach is based on modelling the graphite bricks as rigid bodies connected with non-linear springs and dampers to represent the contacts and clearances. Given the ages of the AGR cores, there is a need to validate the use of GCORE for cores with a large number of components with significant levels of postulated degradation (e.g. 30-50\% doubly cracked bricks and beyond). There is also a requirement to enhance the understanding of core dynamics, especially where components may behave in ways not explicitly modelled by the computational analysis (e.g. behaviour post key disengagement). A suitably representative physical model was required for this purpose.

Since 2008, the University of Bristol (UOB) has conducted an extensive body of technical work that lead to the design and build of a quarter scale physical model of an AGR core, known as the Multi-Layer Array rig (the 'MLA rig'). The scale model development took place in stages of work spanning over 5 years. Figure 1 presents a summary of this phased approach. The theoretical modelling stage investigated the scaling laws that were relevant in model design and established what core components need modelling and what mechanical interactions are relevant for the prototype in its present age-degraded status. The design of the model rig received inputs from previous exploratory testing on small arrays conducted at UOB, as well as from GCORE simulation work. The rig feasibility study was complemented by dynamic testing work on two simpler physical models: a 4x4x8 array ('the Minicore') and a single layer 20-brickacross-array ('the Single Layer Array') that contributed to component and instrument design verification (Dihoru et al 2011). The physical model building and trialling work run in parallel with a collaborative programme of computer simulations using GCORE to simulate the scale model arrangements. An iterative stage of trial testing and rig adaptation lead to the successful commissioning of the MLA physical model in July 2014. Currently, the MLA work is in a production test stage and various array configurations are extensively being tested on the UOB's earthquake simulator. The experimental outcomes will serve as evidence in the AGR's seismic safety cases and as a validation tool for GCORE and other capable computer modelling alternatives. 

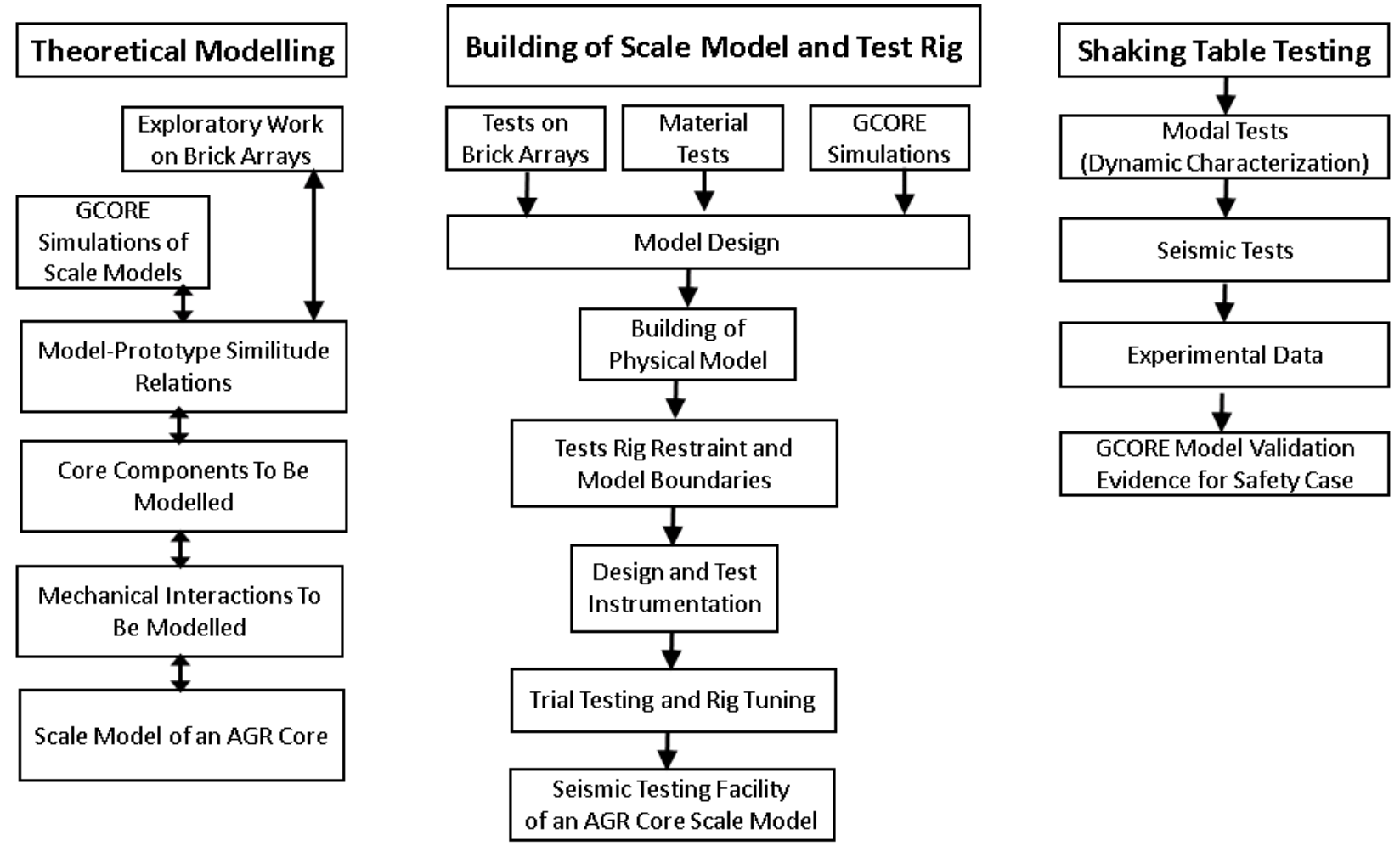

Figure 1. Overview of the MLA research programme

This paper outlines the feasibility study carried out for the design and build of the MLA. The reasoning process underpinning the design is presented together with relevant aspects of instrumentation and rig operation. The MLA is tested on an earthquake simulator ('shaking table') at UOB, with the following objectives set for the experimental and the numerical work:

- Investigate the dynamic behaviour of graphite brick arrays in AGR cores.

- Determine the limits of validity for the current numerical seismic modelling approach under a range of postulated core damage scenarios.

- Quantify the level of margin within the computational assessments.

- Explore the dynamic behaviour of the graphite components beyond the perceived assessment limits.

\section{Feasibility Study and Rig Design}

\subsection{Overview}

The AGR cores consist of thousands of graphite moderator bricks interconnected through a graphite keying system which acts to resist relative motion between bricks. Each graphite core is a 16-sided right prism incorporating an inner cylinder of moderator graphite surrounded (top, bottom and side) by a reflector region. A circular restraint structure consisting of steel beams, steel rods and Warwick links forms the outer boundary of the graphite column assembly. The moderator is the part of the core that forms the subject of this physical modelling study. In the moderator, the graphite components are stacked together in vertical columns that provide the channels for fuel assemblies (308 channels), control rods (81 control rod channels) and coolant flow (Figure 2). The core columns must remain vertical within tight tolerances so that the control rods and the fuel stringers have a secure and unimpeded travel in and out the channels. The vertical faces between neighbouring bricks are separated by gaps to allow for graphite 
expansion during reactor operation. The radial keying system allows free radial movement of the bricks during thermal expansion and contraction of the surrounding steel structures, and provides reaction forces to lateral movement once the clearances between the keys and the keyways have been taken up (Figure 3).

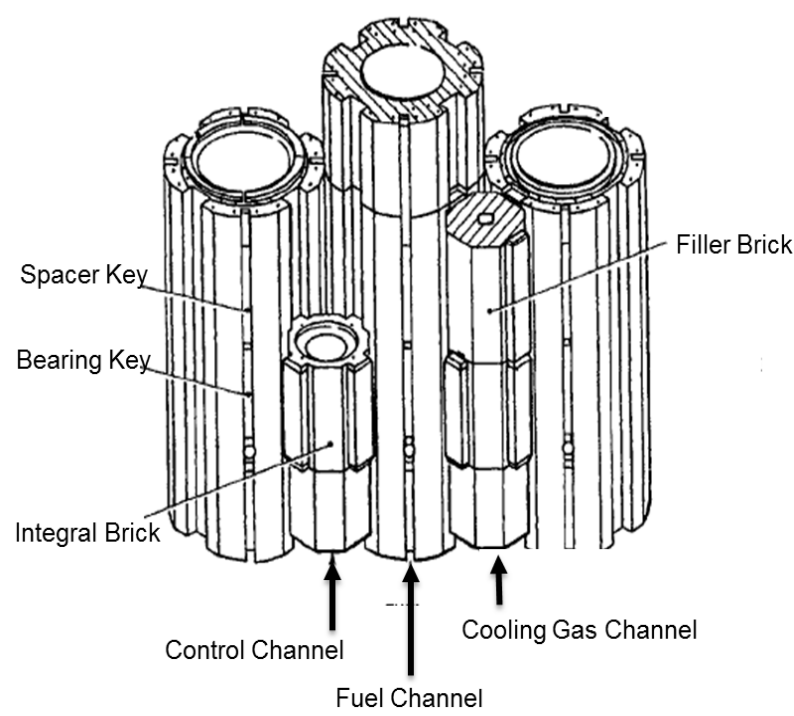

Figure 2. Columns of bricks and keys in an AGR core.
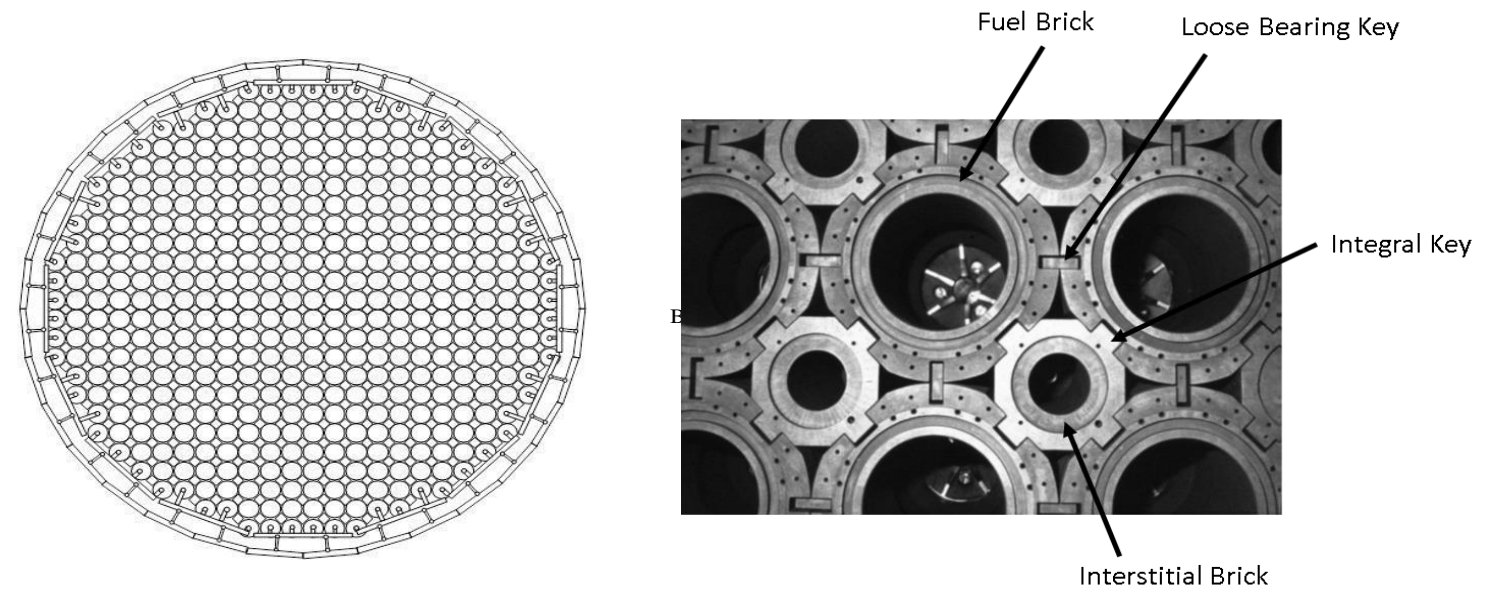

Figure 3. Layout of graphite components in an AGR core showing the array and the enclosing restraint system (left) and the radial keying system (right).

The rig model for seismic testing should be based upon the most highly irradiated AGR cores late in life, that means it should represent increased potential for brick displacements due to component degradation or increased brick-to-brick clearances arising from advanced shrinkage. While the degree of representation of the model for the aforementioned AGR cores is important, the physical model design was primarily guided by the objectives set out by the computer modellers for the validation work. The following aspects of damaged core behaviour have been identified as targets for experimental investigation and such aspects will provide the relevant inputs to the computer model validation work:

- $\quad$ Shape distortion of control channels and channels.

- Core distortion due to variation of horizontal direct clearance between bricks brought about by advanced shrinkage. 
- $\quad$ Core distortion due to large percentage of singly and/or doubly axially cracked bricks.

- $\quad$ Core distortion due to displaced / locked / failed graphite keys.

- $\quad$ Core distortion from crack opening, even if adjacent keys are not damaged.

\subsection{Components And Mechanisms For Modelling}

The complexity of the physical model is generally determined by its number of components and level of precision in reproducing the geometry and scaled dimensions. The more complex the scale model, the higher its level of representation for the dynamic behaviour of a 'generic' prototype. The simpler the physical model, the more sophisticated the mapping software that extrapolates the experimental results should be for a realistic prediction of the prototype response. UOB conducted a study that investigated several candidate rigs from the point of view of their feasibility and from the point of view of their experimental outcomes. Rig feasibility involved aspects such as manufacturing costs, manufacturing time, challenges of design and manufacturing, number of personnel required for handling and testing, complexity and convenience of the measurement system. Out of the possible combinations of components that can be used (Table 1), the single layer array and the hybrid array rigs (Variant No.3) have been selected for the feasibility study. The component interactions and mechanisms relevant for their seismic behaviour are also presented in Table 1.

For the model array, the horizontal restraint system could either be very simply modelled via a ring with various stiffness values or be modelled in a more detailed way to emulate the restraint rod and restraint beam connections. It is important to note that, for a fully representative rig, the provision of a realistic boundary would need additional components and extra space to connect the array bricks to the frame. These additional complications would lead to a loss of focus on the dynamics of the array while increasing assembly and dismantling times. For validation purposes only, the choice of boundary is less constrained as the computer model just needs to represent the rig. Furthermore, for a fully representative rig, a top restraint system would be needed to emulate the behaviour of the missing top layers of bricks and guide tubes, and this would preclude the use of a visual measurement system for the top layer of the array. It was also recognized that adapting the restraint stiffness in the computer model is far simpler than trying to emulate physically such variation. Therefore, it has been decided that the restraint system of the physical rig will be of constant stiffness. Its stiffness value will be sufficiently large for the restraint frame to behave rigidly in the range of frequencies and displacements employed in seismic testing. 
Table 1: Component combinations considered for physical modelling

\begin{tabular}{|c|c|c|c|}
\hline $\begin{array}{c}\text { Variant } \\
\text { No. }\end{array}$ & Components & Interactions/Mechanisms & Observations \\
\hline 1 & $\begin{array}{l}\text { One control channel rig } \\
\text { Fuel bricks (uncracked, singly } \\
\text { cracked and doubly axially } \\
\text { cracked). } \\
\text { Interstitial bricks } \\
\text { Keys (loose, filler) } \\
\text { Filler bricks } \\
\text { Model restraint system }\end{array}$ & $\begin{array}{l}\text { Interstitial channel distortion } \\
\text { Key-keyway disengagement* } \\
\text { Key locking* } \\
\text { Key failure* } \\
\text { Post-disengagement behaviour* } \\
\text { Post-locking behaviour* }\end{array}$ & $\begin{array}{l}\text { This arrangement is mainly to } \\
\text { demonstrate the safe control rod } \\
\text { insertion by monitoring the ' } 3 \text {-point- } \\
\text { angle' of the channel. } \\
\text { "Modelling these aspects is limited by } \\
\text { the insufficient number of components } \\
\text { and oversimplified boundary } \\
\text { conditions }\end{array}$ \\
\hline 2 & $\begin{array}{l}\text { One control channel with } \\
\text { control rod rig } \\
\text { Fuel bricks (uncracked, singly } \\
\text { cracked and doubly axially } \\
\text { cracked). } \\
\text { Interstitial bricks } \\
\text { Keys (loose, filler) } \\
\text { Filler bricks } \\
\text { Control rod } \\
\text { Model restraint system }\end{array}$ & $\begin{array}{l}\text { Interstitial channel insertion } \\
\text { Key-keyway disengagement* } \\
\text { Key locking* } \\
\text { Key failure* } \\
\text { Post-disengagement behaviour* } \\
\text { Post-locking behaviour* }\end{array}$ & $\begin{array}{l}\text { This arrangement is mainly to } \\
\text { demonstrate the safe control rod } \\
\text { insertion by modelling explicitly the } \\
\text { control rods. } \\
\text { "Modelling these aspects is limited by } \\
\text { the insufficient number of components } \\
\text { and oversimplified boundary } \\
\text { conditions }\end{array}$ \\
\hline 3 & $\begin{array}{l}\text { Hybrid Array or Single Layer } \\
\text { Fuel bricks (uncracked, singly } \\
\text { cracked and doubly axially } \\
\text { cracked). } \\
\text { Interstitial bricks } \\
\text { Keys (loose, filler) } \\
\text { Filler bricks } \\
\text { Model restraint system }\end{array}$ & $\begin{array}{l}\text { Key-keyway disengagement } \\
\text { Key locking } \\
\text { Key failure } \\
\text { Post-disengagement behaviour } \\
\text { Post-locking behaviour } \\
\text { Interstitial / fuel channel } \\
\text { distortion } \\
\text { Effect of crack alignment on } \\
\text { brick column stability and key } \\
\text { system functionality. } \\
\text { Variation of gaps between } \\
\text { restraint system and graphite } \\
\text { core during thermal cycling } \\
\text { Variation of brick to brick gaps } \\
\text { as a result of shrinkage. }\end{array}$ & $\begin{array}{l}\text { Getting closer to the true prototype } \\
\text { behaviour is dependent on the number } \\
\text { of model components and the design } \\
\text { of the boundary system. } \\
\text { Control rods need not be explicitly } \\
\text { modelled. Safe control rod insertion } \\
\text { demonstrated via monitoring the ' } 3 \text { - } \\
\text { point-angle' of the channel. } \\
\text { This rig can also investigate the fuel } \\
\text { stringer ' } 3 \text {-point-contact'. }\end{array}$ \\
\hline
\end{tabular}




\subsection{Model Scaling Considerations and Material Selection}

In general physical modelling seeks an adequate approximation of the similitude relations between model and prototype. In this particular case, the following basic prototype and model facts have been considered:

- $\quad$ A graphite density of $1.8 \mathrm{~g} / \mathrm{cm}^{3}$ has been historically assumed.

- $\quad$ An unirradiated Young's Modulus of 9.6 GPa has been assumed. The prototype Gilsocarbon compressive strength is about $80 \mathrm{MPa}$.

- $\quad$ The point contact collisions between components are considered rigid.

- $\quad$ Geometrical similitude is required, including rocking features of model fuel bricks, parallel walls for keys and a dovetail shape for keyways.

- Dimensional precision required (i.e. tolerance of $0.1 \mathrm{~mm}$ or smaller for linear dimensions).

- Key-keyway clearances are scaled for the correct reproduction of rotational and translational movements of the key in the keyway (prototype clearance: $1.04-1.52 \mathrm{~mm}$ ).

- Mechanical properties of the model material should be stable with time, under normal environmental conditions.

- $\quad$ The ideal scaling factor for Young's modulus is 1 . However, this poses severe restrictions on material properties and probably cannot be achieved in practice.

- $\quad$ The scaling factor for gravity is 1 .

- The maximum dimension of model rig is dictated by the size of the shaking table ( $3 \mathrm{~m} \times 3 \mathrm{~m})$.

- The maximum weight of model rig is dictated by the capacity of the shaking table (15 tonnes).

In principle, the models have to be easy to manipulate and to monitor. The larger the scale of the model, the more time is needed to assemble and more effort is required in handling. On the other hand, in smaller scale models the measurements are more difficult to make (i.e. limited space for transducers) and the signal/noise ratio becomes smaller. It is also important to note that the dynamic behaviour of large arrays may be significantly different to that of smaller ones and that a higher degree of sophistication would be required for computer model validations for smaller arrays. Overall, the above arguments are driving the physical modelling choice towards the models with a larger number of components but relaxing the requirement for full AGR core representation. The prototype's maximum horizontal dimension is $\sim 10 \mathrm{~m}$, hence given the size of the shaking table in the UOB's earthquake laboratory, the maximum size model that can be accommodated is a quarter scale model whose footprint is comparable in size to the shaking table platform $(3 \mathrm{~m} \times 3 \mathrm{~m})$.

A summary of scaling factors for earthquake response of structures can be found in (Crewe 1998). In general, a true replica model implies simultaneous duplication of inertial, gravitational and restoring forces and full compliance with the similitude laws. Such a model would require scaling of density and stiffness at the same time. Finding a material whose properties satisfy scaling requirements simultaneously is practically impossible, therefore, an adequate approximation has to be sought. Another method employed in physical modelling is the artificial mass simulation method. It implies the presence of additional material of a non-structural nature to simulate the required density of the model. Such mass can be lumped or distributed. This method is difficult to apply to the scaled AGR core model because of the large number of components that have a role in system's dynamics. Distributing an artificial mass within such a complex array of rigid blocks would be technologically impractical. The third type of modelling applies to cases where gravity forces can be neglected. In the particular case of a graphite core under seismic loading, the gravitational forces cannot be neglected, therefore, using the third type of scaling law is out of the question. It was therefore proposed that the graphite core model should be an 'adequate model' which maintains 'first-order' similarity. 'First-order' similarity implies that the physical parameters with significant influence on the seismic response are accurately scaled, while the 'secondorder' parameters are only be approximately scaled. In this way a modified version of a true replica model 
will be created. For this research programme it was proposed that the geometrical properties of the core would be scaled, as the channel shapes and the general distortion of the core are governed by the brick-tobrick and the key-keyway clearances. It has been decided that the brick and key design will be a quarter scale design based on that of the most irradiated cores. All the clearances in the model will be quarter scaled and determined from those predicted late in their lives. The scaling of material properties has also to consider the dynamic problem that is at the centre of this investigation. During a seismic event, the core will behave as an array of rigid bodies in which the relevant forces are the impact forces generated during the collisions between the components, the gravitational and the restoring forces. As impact forces depend on the local contact properties (i.e. contact stiffness and coefficient of restitution), then the Young's modulus of the component material becomes relevant in scaling. It is important to observe, that the contact properties are different for the normal and for the shear contact. The energy restitution after a brick-to-brick collision depends heavily on the actual layout of components in a zone of investigation (i.e. presence or absence of bearing key, presence or absence of integer key, locking of key, etc). Brick-tobrick testing of model components have been carried out to determine the values of contact properties for various component combinations. The selection of the model material has to seek a reasonable approximation for the ratio between the scaling factor for density $\left(S_{r}\right)$ and the scaling factor for stiffness $\left(S_{E}\right)$ of the model component. This ratio is described by the basic scaling law in Equation 1:

$$
S_{\rho}=S_{E} / S_{L}
$$

where $S_{L}$ is the scaling factor for length. For a quarter scale model, Equation 1 becomes:

$$
S_{\rho}=4 \times S_{E}
$$

Table 2 presents the results of Equation 2 for a number of candidate materials.

Table 2: Scaling factors for density and stiffness for candidate model materials

\begin{tabular}{|l|c|c|c|c|c|c|}
\hline Material & $\begin{array}{c}\text { Density } \\
\left(\mathbf{k g} / \mathbf{m}^{\mathbf{3}}\right)\end{array}$ & $\begin{array}{c}\text { Young's } \\
\text { Modulus (GPa) }\end{array}$ & $\begin{array}{c}\text { Compressive Strength } \\
(\mathbf{M P a})\end{array}$ & $\mathbf{S}_{\boldsymbol{\rho}}$ & $\mathbf{S}_{\mathbf{E}}$ & $\mathbf{S}_{\boldsymbol{\rho}} / \mathbf{S}_{\mathbf{E}}$ \\
\hline $\begin{array}{l}\text { Commercial } \\
\text { Graphite }\end{array}$ & 1800 & 9.60 & 70 & 1.00 & 1.00 & 1.00 \\
\hline Nylon 12 & 1020 & 1.80 & 75 & 0.57 & 0.19 & 3.02 \\
\hline POM & 1410 & 2.70 & 90 & 0.78 & 0.28 & 2.79 \\
\hline Reinforced POM & 1580 & 9.00 & 100 & 0.88 & 0.94 & 0.94 \\
\hline PPS(Fortron) & 1600 & 13.00 & 93 & 0.89 & 1.35 & 0.66 \\
\hline LCP(Vectra) & 1610 & 13.00 & 90 & 0.89 & 1.35 & 0.66 \\
\hline $\begin{array}{l}\text { Aluminium } \\
\text { Alloy }\end{array}$ & 2700 & 70.00 & 110 & 1.50 & 7.29 & 0.21 \\
\hline
\end{tabular}

Note: Property values are indicative. POM is the DIN abbreviation for polyoxymethylene. PPS (Fortron ${ }^{\circledR}$ ) is polypheniline sulphate with $40 \%$ glass reinforcement. LCP $(V e c t r a ß)$ is a liquid crystal polymer with $30 \%$ glass reinforcement (supplier: Ticona Ltd UK).

The friction between the surfaces in contact within the array is another property of interest. Table 3 presents the static and the dynamic coefficient of friction for various combinations of candidate materials that were investigated. 
Table 3: Friction coefficients for selected pairs of materials

\begin{tabular}{|c|l|l|c|c|}
\hline No. & \multicolumn{1}{|c|}{ Material 1 } & \multicolumn{1}{c|}{ Material 2 } & $\boldsymbol{\mu}_{\text {static }}$ & $\boldsymbol{\mu}_{\text {dynamic }}$ \\
\hline 1 & POM & Steel & 0.14 & 0.21 \\
\hline 2 & POM & POM & 0.19 & 0.15 \\
\hline 3 & POM & PA (Polyamide) & 0.04 & 0.06 \\
\hline 4 & POM+20\% PTFE & PA + 20\% PTFE & 0.03 & 0.04 \\
\hline 5 & Graphite (temp 20 deg C) & Graphite (temp 20 deg C) & 0.10 & 0.10 \\
\hline 6 & Graphite (temp 350 deg C) & Graphite (temp 350 deg C) & 0.20 & 0.20 \\
\hline 7 & Aluminium (dry) & Aluminium (dry) & 1.05 & 1.40 \\
\hline 8 & Aluminium (greasy) & Aluminium (greasy) & 0.30 & 0.32 \\
\hline
\end{tabular}

Note: Property values are indicative. POM is the DIN abbreviation for polyoxymethylene.

Based on these results, the engineering thermoplastic polyoxymethylene (DIN-abbreviated POM) has been identified as the strongest candidate for the array component manufacturing. POM exhibits a reasonable density/stiffness ratio and high rigidity which makes it suitable for precision machining. POM is catalogued as non-hygroscopic, therefore the component dimensional tolerances are likely to be stable with time in normal environmental conditions. POM also exhibits comparable friction coefficients with the graphite bricks at reactor operating temperature (Table 3). Two colours, natural and black, were available and the choice of which components would be white and which black was made so as to minimise assembly errors by differentiating components of similar but different shapes, and to provide visual contrast when observing the experiments. A matte finish was chosen to minimise reflections which could affect the performance of the measurement vision systems that work best under low light noise conditions.

\subsection{Considerations of Dynamic Behaviour}

The smaller and stiffer the array, the smaller the relative displacements between the components, making measurement more challenging. Previous measurements on small array tests (Roscow et al 2010) show that the displacements in a 10x10x1 section are $\sim 10 \mathrm{~mm}$ maximum for the $100 \%$ cracked core, but only $\sim 5 \mathrm{~mm}$ for the $50 \%$ cracked core, and as small as $\sim 1 \mathrm{~mm}$ for the intact core. It is also important to note, that smaller and stiffer models are likely to respond at higher frequencies and that such behaviour would be a departure from the actual prototype for which a 'natural frequency' of $2-3 \mathrm{~Hz}$ has been historically assumed. Lowering the 'natural frequency' of the model can be done via increased slackness in the system. As the horizontal clearance value should be representative of late life operations (i.e. it has a welldefined scaled value), then slackness can be increased via increased key-keyway clearances and/or via increased area section of the model. If the key-keyway clearances are to be kept quarter-scale of the prototype value, then the only route for increasing slackness is via a larger model section. This has lead to the decision to design and build a near-full core multi-layered array rig (MLA) with the following characteristics: quarter scale, octagonal shape, 20 bricks across the horizontal cardinal dimension and 8 layers. The model components, including the model doubly cracked bricks are shown in Figure 4. The base of the rig (Layer 1) (Figure 5) is a seating assembly of plastic plates that allow only radial rocking. More than one such grid bases may be used in the future, to emulate several values of horizontal direct clearance between bricks. The model represents the inner-most 10 rings of the AGR core (Figure 4). Because the experiment was intended to study the dynamic behaviour of the array, the flexibility and dynamics of the actual core restraint mechanism was not represented. The boundary frame was designed to be dynamically rigid within the seismic test range (i.e. natural frequencies above $35 \mathrm{~Hz}$ ). The lateral boundary restraint arrangements provides the required rigidity of the perimeter model bricks, while 
allowing for sufficient adjustment to accommodate the required brick pitches and gaps. The restraint base frame is rigid and allows for precise levelling of the base plastic plate assembly on which the model bricks are founded.
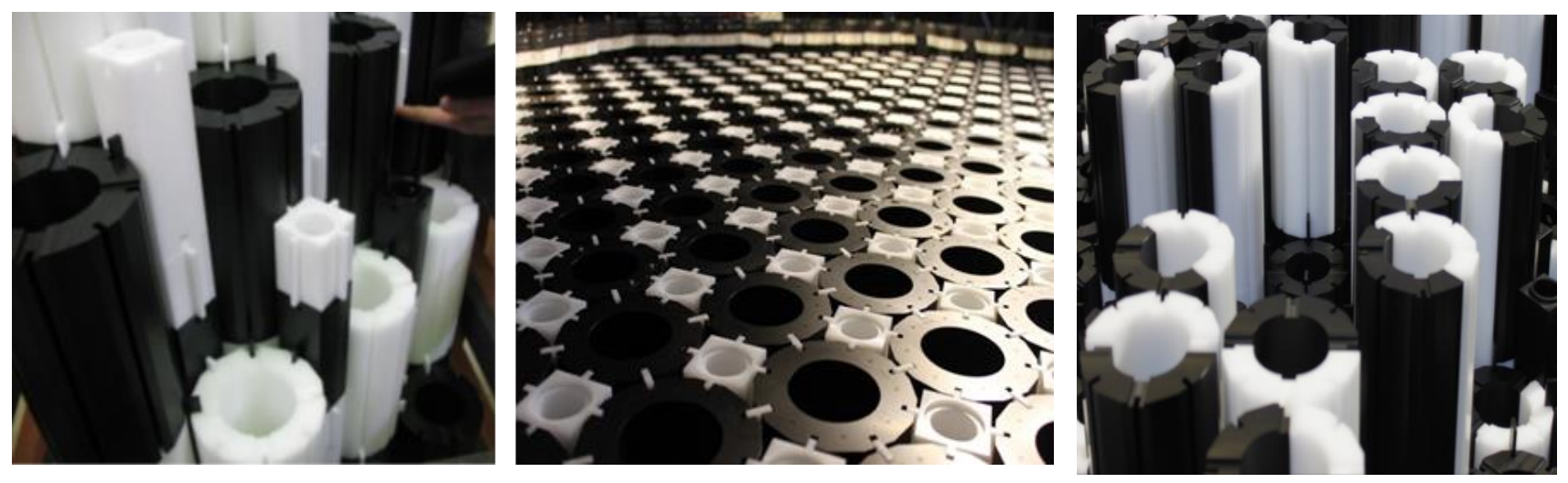

Figure 4. Quarter scale POM components in the MLA rig (left: columns, middle: top layer, right: model doubly cracked bricks).
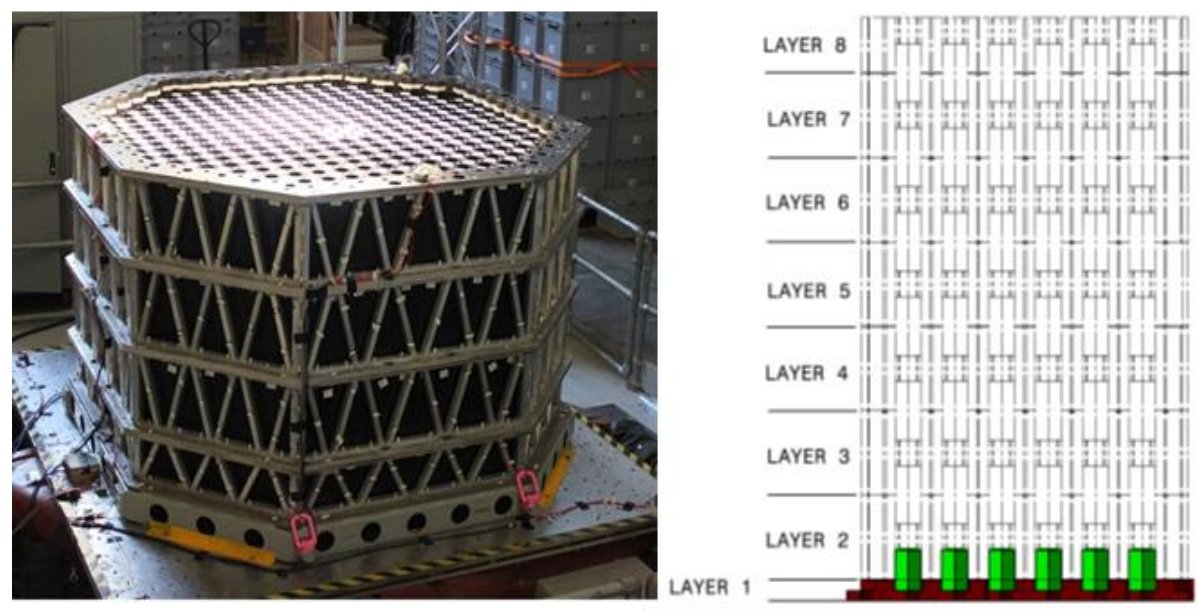

Figure 5. The ML restraint (left). Layer layout in the MLA rig (right). Layer 1 is an assembly of plastic plates. Layers 2-8 are active. (courtesy Atkins).

\subsection{Array Component Design and Manufacturing}

The MLA rig contains quarter scale model components of fuel bricks (called 'lattice bricks' in the rig), interstitial bricks, loose bearing keys, filler keys and spacer keys, and takes into account the effects of the core late in life and the associated changes in graphite component geometries. The array components were manufactured via a combined process of extrusion, machining of stock shapes, annealing and precision machining that can secure linear tolerances down to $0.05 \mathrm{~mm}$. The rig takes into account the effects of keyway root cracking resulting in singly and doubly-cracked bricks. Arrays with up to 50\% doubly cracked bricks in Layers 4-7 and up to 10\% doubly cracked bricks in Layer 8 can be currently built in the MLA rig. The level and the pattern of cracking can be varied according to the numerical validation needs. 


\subsection{Measurements and Instrumentation}

The MLA testing programme consists of one-axis shaking table tests in the horizontal plane. The physical parameters that are measured in the rig and the instrumentation employed for this purpose are given in Table 4.

Table 4: Instruments and measurands in MLA rig testing

\begin{tabular}{|l|l|}
\hline \multicolumn{1}{|c|}{$\begin{array}{c}\text { Instrument/ Measurement } \\
\text { System }\end{array}$} & \multicolumn{1}{c|}{ Measurands } \\
\hline Infrared Vision System (IRVS) & Displacement of array components, ML restraint frame, shaking table \\
\hline $\begin{array}{l}\text { High Speed Video System } \\
\text { HSVS) }\end{array}$ & Displacement of array components in top layer \\
\hline Accelerometers (SETRA type) & Acceleration of shaking table and ML restraint frame \\
\hline Accelerometers (MEMS* type) & Acceleration of interstitial/filler/fuel bricks \\
\hline Hall Effect Sensors & Interstitial channel profile and loose bearing key position in the keyway \\
\hline Linear Potentiometric Transducers & Fuel channel profile \\
\hline \multicolumn{1}{|c|}{ Note: MEMS* stands for Micro-Electro-Mechanical-System } \\
\hline
\end{tabular}

The lattice (fuel) channel measurements are obtained with potentiometric transducers installed on the bottom face of each model lattice brick in the instrumented column (Figure 6.1). Each filler and integrally keyed brick in the instrumented interstitial columns are equipped with a 3 -axis accelerometer, while each lattice brick in the instrumented lattice columns contains 2 off 3 -axis accelerometers (at the top and bottom). The interstitial channel profiles are measured using Hall effect sensors mounted on both the top and bottom faces of each filler brick (Figure 6.2) in the instrumented column. Sets of three magnets are embedded in the vertically adjacent integrally keyed bricks (Figure 6.3) to interact with the Hall effect sensors in the filler bricks. These produce sensor voltages that can be converted into 6 DOF (degrees of freedom) of the filler-to-interstitial brick interface. The channel sensor outputs are acquired by a novel distributed micro data acquisition system (microDAQ) system consisting of a multitude of 16/32channel DAQ systems hosted by the instrumented filler and the instrumented lattice bricks. The brick interface measurements are integrated up the columns to generate channel profiles. The MLA array also contains a pattern of infrared markers rigidly attached to selected components in the top layer that can be tracked by an infrared camera system. Figure 6.4 shows an example of 3 infrared markers (A, B and C) attached to a lattice brick in the top layer.
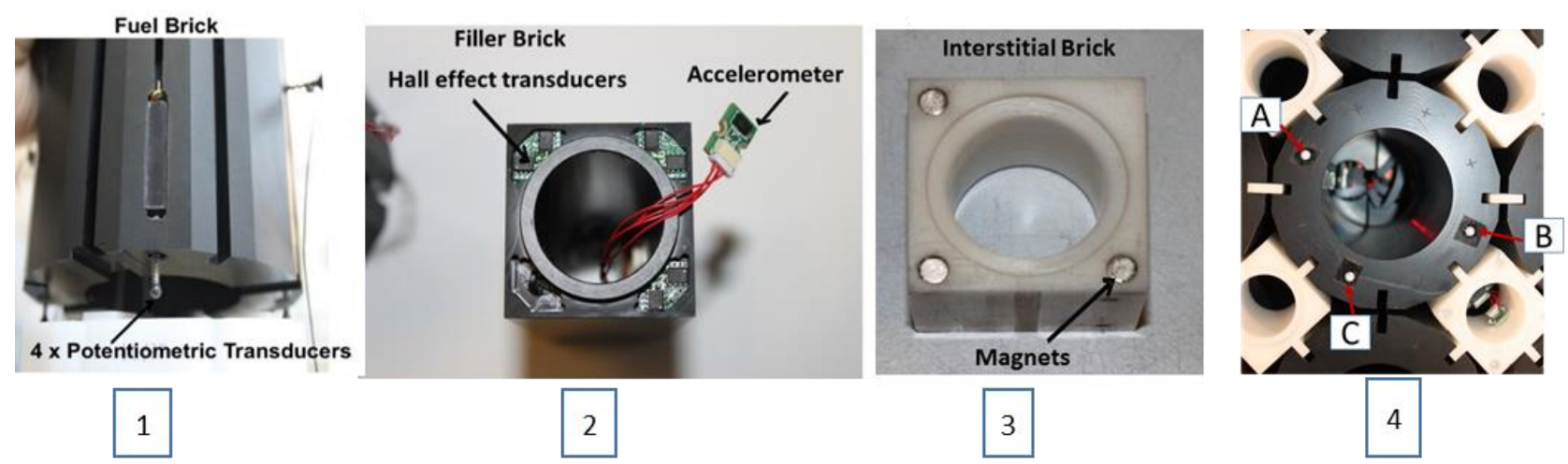

Figure 6 Instruments in the MLA - 1: instrumented lattice brick, 2: instrumented filler brick, 3: instrumented interstitial brick, 4: lattice brick with infrared markers (A, B and C).

A selection of model doubly cracked bricks (DCBs) are equipped with magnets and Hall effect transducers to measure the 6DOF displacement of one half relative to the other half (Figure 7). 

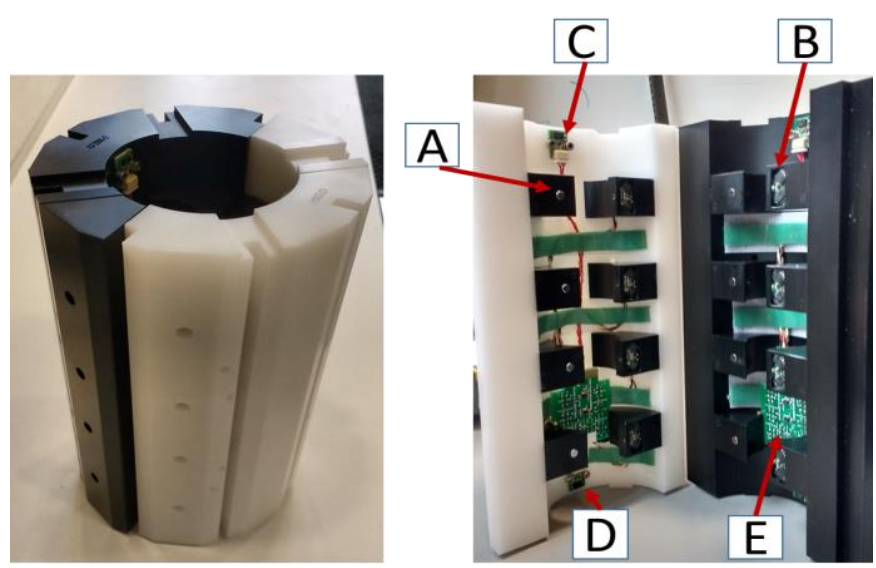

Figure 7 Instrumented doubly cracked brick: A: magnets, B: Hall effect sensors, C and D: triaxial accelerometers, E: terminal board for the microDAQ system.

A summary of rig component and instrument numbers deployed in the rig is presented in Table 5, and the rig data flow and data acquisition (DAQ) are explained in Figure 8. The conventional DAQ system (Conv DAQ) acquires data from an array of accelerometers deployed on the MLA restraint system and on the shaking table platform. The Micro DAQ acquires data from the instrumentation located inside the array components and the infrared and the high speed video systems are tracking the components in the top layer. All these different DAQ systems are synchronized via a common clock signal.

Table 5: Summary of component and instrument numbers in the MLA rig.

\begin{tabular}{|l|c|}
\hline & Number \\
\hline Model array components & $\sim 44000$ \\
\hline Sensors for One Lattice Column Profile & 82 \\
\hline Sensors for One Interstitial Column Profile & 195 \\
\hline Sensors for One Loose Bearing Key Monitoring & 12 \\
\hline Sensors for One Cracked Brick Monitoring & 32 \\
\hline $\begin{array}{l}\text { Number of Sensors for 10 Pairs of Instrumented Columns, 10 } \\
\text { Instrumented DCBs, 10 Instrumented Keys }\end{array}$ & 3210 \\
\hline
\end{tabular}




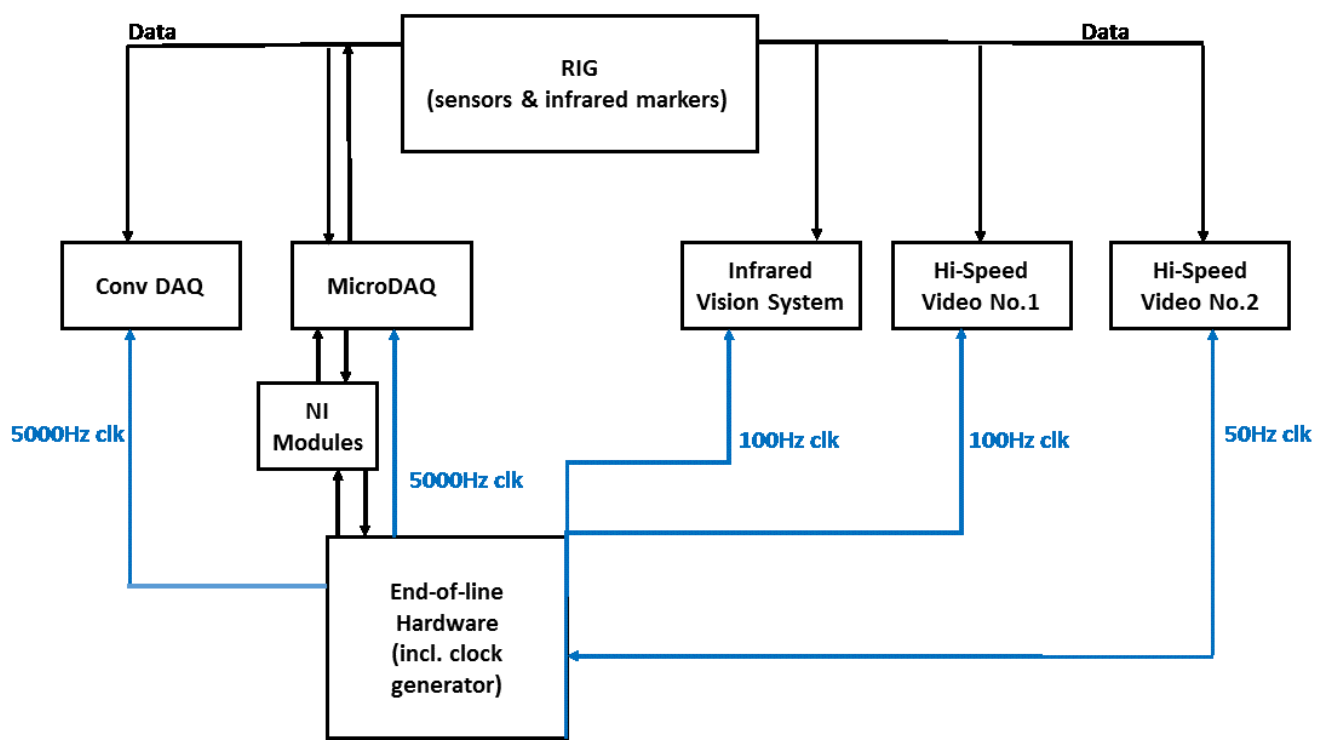

Figure 8. Diagram showing MLA rig data acquisition systems and data communication.

\section{Typical Rig Outputs}

The MLA programme of testing is driven by the computer modeller needs, being designed to generate results for comparison against primary GCORE model outputs such as brick-to-brick displacements and channel profiles. The main objectives are to reduce the uncertainties in the numerical tool, to investigate the interactions between keys and keyways before and after disengagement and to investigate how far the current assessment limits are from cliff-edge behaviour. The focus of testing is on scaled input motions that are derived from the hazard inputs and resulting responses predicted by the seismic assessments of the UK's AGR stations. The seismic inputs are applied as directional rosettes with $22.5^{\circ}$ or $45^{\circ}$ increments, at acceleration magnitudes varying from $0.05 \mathrm{~g}$ to $1 \mathrm{~g}$. A summary of typical inputs employed in testing is presented in Table 6.

Table 6 Typical inputs employed in MLA testing

\begin{tabular}{|c|l|c|l|}
\hline Input Type & \multicolumn{1}{|c|}{ Input Characteristics } & $\begin{array}{c}\text { Input } \\
\text { Direction }\end{array}$ & \multicolumn{1}{|c|}{ Comments } \\
\hline $\begin{array}{c}\text { White } \\
\text { noise }\end{array}$ & $\begin{array}{l}\text { Frequency range: } 0-100 \mathrm{~Hz} \\
\text { Acceleration amplitude }\left(\mathrm{RMS}^{*}\right): 0.1 \mathrm{~g}, 0.2 \mathrm{~g}, 0.3 \mathrm{~g}\end{array}$ & $\mathrm{X}, \mathrm{Y}$ & $\begin{array}{l}\text { Modal testing for MLA restraint with } \\
\text { and w/o array. Explore resonant } \\
\text { frequencies. Investigate symmetry of } \\
\text { restraint. }\end{array}$ \\
\hline $\begin{array}{c}\text { Sinusoidal } \\
\text { dwell }\end{array}$ & $\begin{array}{l}\text { Frequency: } 1 \mathrm{~Hz}, 2 \mathrm{~Hz}, 3 \mathrm{~Hz}, 4 \mathrm{~Hz}, 5 \mathrm{~Hz} \\
\text { Acceleration amplitude (pk-pk*):0.1g, 0.25g, 0.3g, } \\
0.8 \mathrm{~g}\end{array}$ & $\mathrm{X}, \mathrm{Y}$ & $\begin{array}{l}\text { Explore frequency response and ability } \\
\text { to replicate basic mechanics. }\end{array}$ \\
\hline Seismic & $\begin{array}{l}\text { Time history generated from secondary response } \\
\text { spectra at AGR power stations, 10e-4 probability of } \\
\text { occurrence. Time scaled (time scaling factor*=2) }\end{array}$ & rosette & $\begin{array}{l}\text { Explore onset of changes of behaviour. } \\
\text { Amplification of response for certain } \\
\text { frequencies and energy bands. } \\
\text { Effect of input scaling on response. }\end{array}$ \\
\hline Seismic & $\begin{array}{l}\text { Time history generated from secondary response } \\
\text { spectra at AGR power stations, 10e-4 probability of } \\
\text { occurrence. Unscaled }\end{array}$ & rosette & \\
\hline
\end{tabular}

*RMS: Root Mean Square (quadratic mean of acceleration); *pk-pk: peak to peak; *time scaling factor of 2 derived from length scaling factor of 4. 
Figures 9 and 10 present examples of experimental outputs obtained in seismic tests conducted on an array configuration that contained 50\% DCBs in layers 4-7 and only intact bricks in layer 8 (top layer). The tests employed a Required Response Spectrum (RRS) compatible Eurocode input motion applied on $\mathrm{X}$ direction, at three levels of peak shaking table acceleration, i.e. $0.05 \mathrm{~g}, 0.45 \mathrm{~g}$ and $0.75 \mathrm{~g}$. The contours of maximum relative lattice brick displacement with respect to the rigid frame are shown in Figure 9. The response appears to be approximately symmetrical, with the maximum relative displacements recorded in the central part of the array. In general, the array behaviour is displacement driven, being governed by the brick-to-brick and the key-keyway clearances. The relative movements of the bricks in the central region of the array move more, due to gap accumulation effects, than the bricks at the periphery whose movements are restricted by the presence of the frame boundary. The maximum relative displacement increases with input from $\sim 2 \mathrm{~mm}$ in T2042 to $\sim 5 \mathrm{~mm}$ in T2489.

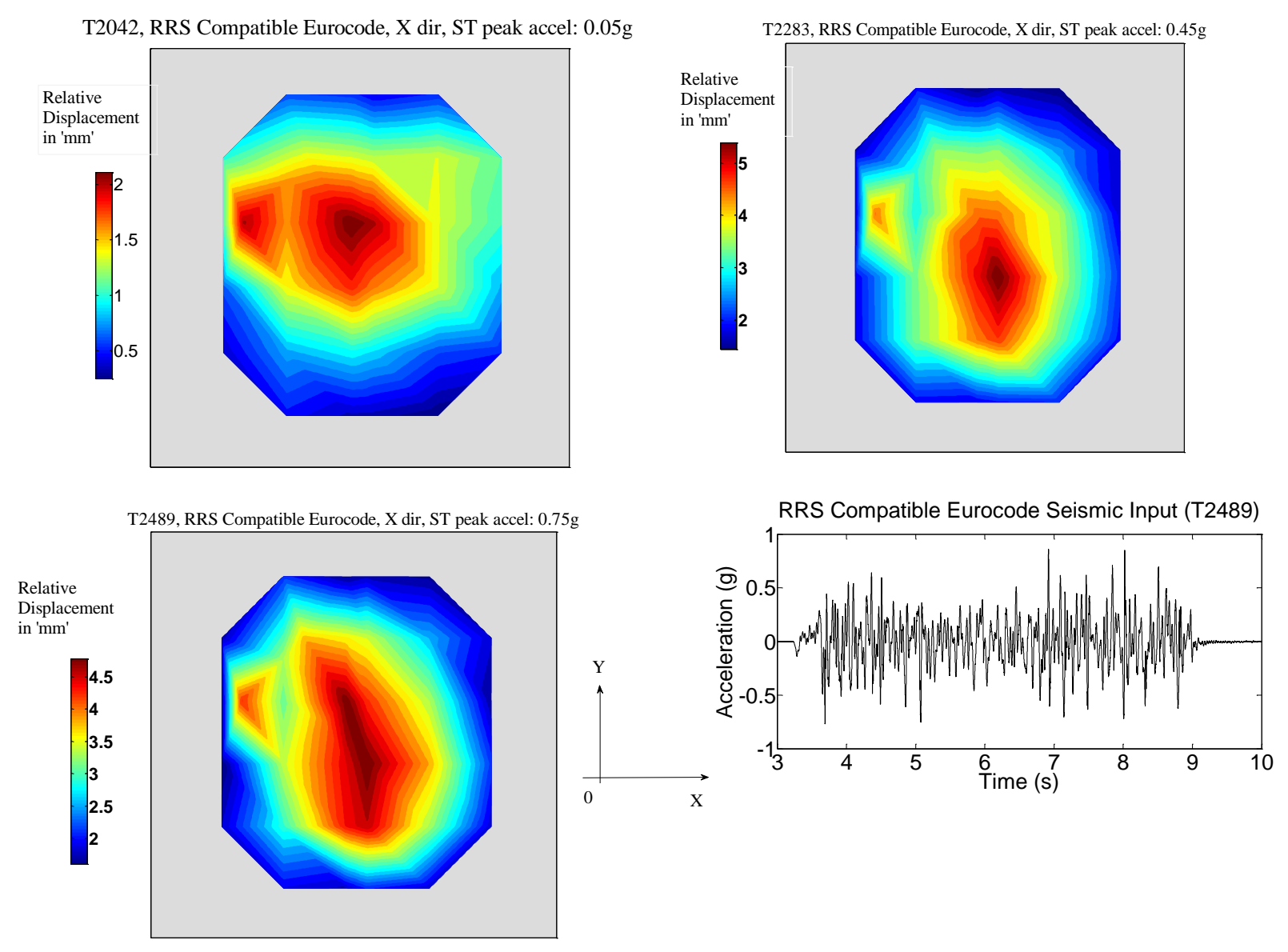

Figure 9 Contours of maximum relative displacement for the lattice bricks in the top layer, for RRS compatible Eurocode seismic input, applied on X direction, at three levels of peak shaking table acceleration (array with 50\% DCBs in layers 4-7).

Figure 10 presents the loci of maximum deflection in the same tests as above, for one representative lattice column (i.e. LC2521) and one representative interstitial column (IC2622). The channel profiles show increasing levels of deflection as the input acceleration increases. The columns behave like beams restricted at the bottom, with maximum deflection recorded towards the top of the array. At low level excitation $(0.05 \mathrm{~g})$ the maximum deflection is at the top, while at higher excitation levels the maximum 
deflection is a couple of layers below the top. This is to be expected, with the intact layer 8 restricting the deflection of columns at the top ('anchoring' effect).
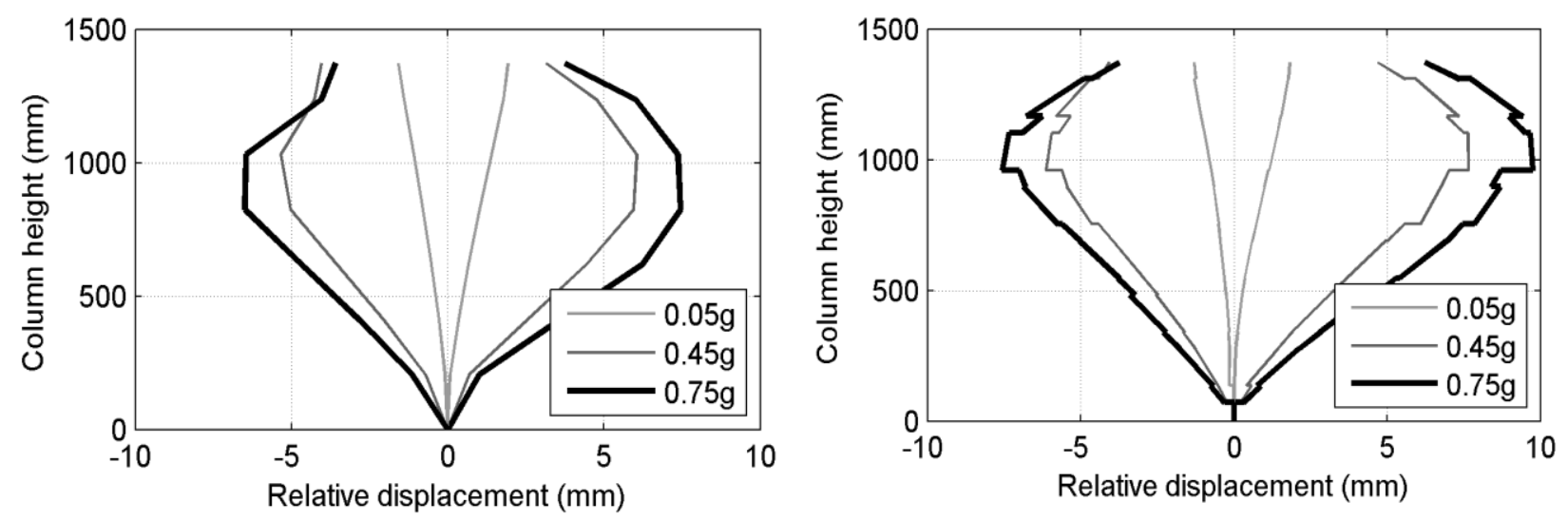

Figure 10 Maximum deflection profiles for instrumented lattice column LC2521 (left) and instrumented interstitial column IC2622 (right), for HPB seismic input at three levels of peak shaking table acceleration.

The rig can provide extensive displacement mapping of the top layer response and channel profile response data for selected lattice and control channels. The data will be employed directly for tuning and validating the existing numerical models and also in parametric studies to enhance the understanding of core dynamics.

\section{Conclusions}

The development of a quarter scale physical model of the array of graphite bricks in an AGR core has been presented. The decision making process that underpinned the rig design and build, which included investigations of model scaling, material selection and instrumentation design, has been described. The MLA rig is a tool of high complexity, unique in the world: its number of model components and measurement sensors are pushing the boundaries of design in instrumentation, data acquisition and data processing. The rig can provide displacement and acceleration data for the array components, as well as channel profile measurements for a wide range of dynamic inputs. Its role is to provide experimental validation of the existing numerical models that support the AGR seismic resilience assessments. The rig is versatile in terms of array component configuration and instrumentation layout, hence a variety of core scenarios can be tested that can explore in detail the mechanics of these complex structures.

\section{Acknowledgement}

The authors would like to thank EDF Energy for financial and technical support. The views expressed in this paper are those of the authors and do not necessarily represent those of EDF Energy.

\section{References}

Crewe, A. J. (1998). The Characterisation and Optimisation of Earthquake Shaking Table Performance, PhD Thesis, University of Bristol, United Kingdom. 
Dihoru L, Crewe, A.J, Taylor, C.A., Horgan, T. (2011), Shaking Table Experimental Programme, Proc. of the Conference on Modelling and Measuring Reactor Core Graphite Properties and Performance, Aston University,. Edited by Gareth B. Neighbour, Cambridge, UK.

Flewitt and Wickham (2015) (eds), Engineering Challenges Associated with the Life of Graphite Reactor Cores, EMAS Publishing, ISBN-978-0-9576730-5-2.

Kralj, B., Humphreys, S.J. and Duncan, B.G.J. (2005). Proc. of the Conference on Seismic Modelling of an AGR Nuclear Reactor Core, Cardiff, United Kingdom, 193-200.

Neighbour, G.B. (2007) (ed), Management of Aging Processes in Graphite Reactor Cores, RSC Publishing, Cambridge. ISBN-978-0-85404-345-3.

Neighbour, G.B. (2013) (ed), Modelling and Measuring Reactor Core Graphite Properties and Performance, RSC Publishing, Cambridge, ISBN-978-1-84973-390-8.

Roscow, A.R., Skelton, J. and McLachlan, N. (2010), Continuing Development of the Quarter Scale Core Model to Support the Safe Performance of AGR Cores, Proc. of Securing the Safe Performance of Graphite Reactor Cores Conference, University of Nottingham, United Kingdom, 203-209. 